\title{
NAVIER-STOKES ANALYSIS OF SCALE EFFECTS ON ABLATION IN CARBON-CARBON ROCKET NOZZLES
}

\author{
D. Bianchi ${ }^{1}$, F. Nasuti ${ }^{1}$, E. Martelli ${ }^{2}$, and M. Onofri ${ }^{1}$ \\ ${ }^{1}$ Sapienza University of Rome \\ Dipartimento di Meccanica e Aeronautica \\ Via Eudossiana 18, Rome I-00184, Italy \\ ${ }^{2}$ Second University of Naples \\ Dipartimento di Ingegneria Aerospaziale e Meccanica \\ Via Roma 29, Aversa, CE I-81131, Italy
}

\begin{abstract}
A study is conducted to predict carbon-carbon nozzle recession behavior in solid rocket motors (SRM) for wide variations of propellant formulations and motor operating conditions. The numerical model considers the solution of Reynolds averaged Navier-Stokes (RANS) equations in the nozzle, heterogeneous chemical reactions at the nozzle surface, variable transport and thermodynamic properties, and heat conduction in the nozzle material. Results show that the ablation rate is affected by the dimension of the nozzle as well as by the boundary layer thickness at the nozzle entrance. The combined effect of both scale and boundary layer thickness at the nozzle entrance is also analyzed.
\end{abstract}

\section{INTRODUCTION}

With the development of high-energy solid propellants and harder firing conditions in advanced SRM, carbon/carbon (C/C) materials have found increasing application in SRM nozzles because of their excellent thermal and physical properties and low densities. However, the hostile thermochemical environment resulting from the high-performance solid propellants creates many problems to such materials. One of the serious problems is the erosion/recession of the rocket nozzle material. As the propellant of the rocket motor burns, the nozzle is exposed to the hot propellant combustion products which form a turbulent

This is an Open Access article distributed under the terms of the Creative Commons Attribution-Noncommercial License 3.0, which permits unrestricted use, distribution, and reproduction in any noncommercial medium, provided the original work is properly cited. 
boundary layer over the nozzle surface. The hot products transfer energy to the nozzle wall, causing the surface temperature to rise and, hence, increasing the reactivity of the nozzle material. At high surface temperatures, heterogeneous chemical reactions occur between the nozzle material and oxidizing species such as $\mathrm{H}_{2} \mathrm{O}$ and $\mathrm{CO}_{2}$, normally found in a significant amount in the combustion stream. Heterogeneous reactions consume the oxidizing species at the nozzle surface and produce carbon monoxide $\mathrm{CO}$ : the result is the thermochemical erosion of the nozzle. Such erosion is most severe at the throat due to the maximum heat-transfer rate in that region. As the nozzle throat area increases, thrust decreases and, thus, the motor performance reduces especially in long-duration firings.

The classic way to measure performance reduction is to test full-scale motors, but this takes a long time and is very expensive because tests must be repeated for every new motor. A complementary method is to establish regression models that can accurately predict the regression rate of nozzle throat, but these models require a fundamental knowledge of the major mechanisms that drive the regression rate. The identification and description of the major mechanisms governing the nozzle erosion have been the subject of many investigations [1$6]$ in solid rocket technology. As mentioned above, the most reactive gases are $\mathrm{H}_{2} \mathrm{O}$ and $\mathrm{CO}_{2}$, which react with carbon to form carbon monoxide [3-8]. The overall rate of these reactions depends on their kinetics as well as on the rate at which the oxidizing species can diffuse across the boundary layer to the nozzle surface. If the kinetic rates are much higher than the diffusion rates, the recession rate is determined primarily by the diffusion mechanism of oxidizing species (diffusion-limited). The other extreme situation is that of high diffusion rates and low kinetic rates, in which case the recession is predominantly determined by the chemical kinetics (kinetic-limited). The overall nozzle erosion process is extremely complex with the interplay of numerous factors including the solidpropellant composition, motor operating conditions, duration of firing, nozzle geometry and material properties, rates of diffusion of the species toward the surface through the boundary layer, and chemical reactions at the surface and in the gas phase.

In addition to the aerothermochemical processes, the erosion may have contributions from the mechanical processes caused by impact of condensed metaloxide particles (e.g., $\mathrm{Al}_{2} \mathrm{O}_{3}$ ) on the nozzle surface or by the structural failure because of high thermal stresses. However, the chemical erosion is the primary reason for the nozzle recession [1-3].

The objective of this work is to study how the erosion process is affected by the nozzle scale effects as well as by the boundary layer thickness at the nozzle entrance. The adopted model is based on a full Navier-Stokes approach coupled with a thermochemical equilibrium ablation model for predicting erosion rate of $\mathrm{C} / \mathrm{C}$ SRM nozzles. In particular, heterogeneous chemical reactions at the nozzle surface, rate of diffusion of the species through the boundary layer, heat 
conduction inside the $\mathrm{C} / \mathrm{C}$ material, and variable multispecies thermophysical properties are taken into account.

\section{THEORETICAL MODEL}

In the present formulation, the gas-phase dynamics is based on the full NavierStokes equations for single-phase multicomponent reacting systems where variable thermodynamic and transport properties are accounted for. The heat conduction process in the nozzle is accounted for and treated as being onedimensional and steady-state.

Because of the chemically active surface, further physical modeling is necessary for the gas/surface interaction. To complete the formulation of the theoretical model, boundary conditions must be specified at the gas/solid interface which describe the physics of the surface phenomena. A detailed description of the governing equations and the gas/surface boundary conditions is reported in [9]. Here, it suffices to say that the surface mass and energy balances are imposed at the gas/solid interface to calculate the surface erosion rate and temperature, respectively. For a chemically reacting, graphitic ablating surface, the surface, mass balance is:

$$
\left.\rho D_{i m} \frac{\partial y_{i}}{\partial \eta}\right|_{w}+\dot{m}_{i}=(\rho v)_{w} y_{i_{w}} \quad\left(i=1, \ldots, N_{c}\right)
$$

where $\dot{m}_{i}$ is the source term due to gas-surface interaction; $\rho$ is the density; $v$ is the velocity component normal to surface; $D_{i m}$ is the diffusion coefficient of species $i$ with respect to mixture; $y_{i}$ is the species mass fraction; $N_{c}$ is the number of species in the mixture; $\eta$ is the outward coordinate normal to surface; and the subscript ()$_{w}$ indicates gas properties at the gas-solid interface. Note that the term on the right-hand side is the mass transfer due to convection.

The surface energy balance is:

$$
\left.k \frac{\partial T}{\partial \eta}\right|_{w}+\left.\sum_{i}^{N_{c}} h_{i_{w}} \rho D_{i m} \frac{\partial y_{i}}{\partial \eta}\right|_{w}+\dot{m} h_{s}=(\rho v)_{w} h_{w}-\left.k_{s} \frac{\partial T_{s}}{\partial r}\right|_{s}
$$

where $\dot{m}$ is the mass flow due to ablation; $k$ is the thermal conductivity; $T$ is the temperature; $h$ is the enthalpy; $r$ is the inward coordinate normal to surface; and the subscript ()$_{s}$ indicates solid properties at the gas-solid interface. Note that the second term on the right-hand side is the heat conduction in the solid material. The heterogeneous reactions between the exhaust gases and the carbon consume the oxidizing species at the nozzle surface and, thereby, create concentration gradients in the boundary layer. These gradients result in the diffusion of oxidizing species to the nozzle surface. In this work, it is assumed 
that local chemical equilibrium is established at the solid-gas interface and, hence, the erosion process is considered diffusion-limited. This assumption is described in more details in [9].

\section{NUMERICAL PROCEDURE}

The analysis of the nozzle flow field is performed by a two-dimensional (2D) reacting turbulent RANS solver [10], which is based on the lambda scheme developed by Moretti [11]. The thermodynamic properties for individual species are approximated by seventh-order polynomials of temperature while the transport properties are approximated by fourth-order polynomials [12]. Mixture properties for conductivity and viscosity are derived from the Wilke's rule. The diffusion model is based on an effective diffusion coefficient obtained assuming a constant Lewis number. The Spalart-Allmaras one-equation model [13] is used to compute the turbulent viscosity $\mu_{t}$. Turbulent conductivity and turbulent mass diffusivity are computed from $\mu_{t}$, specific heat at constant pressure, turbulent Prandtl number (a standard value of 0.9 is assumed), and turbulent Schmidt number (a standard value of 0.9 is assumed). All computations are made considering bulk graphite $\left(\rho_{s}=1.83 \mathrm{~g} / \mathrm{cm}^{3}\right)$ as the nozzle material, whose thermodynamic properties as a function of temperature are taken from literature data [12]. Assuming surface equilibrium, the chemical composition at the nozzle wall $\left(y_{i_{w}}\right)$ can be obtained using a free energy minimization procedure [12]. The ablation mass rate is then computed from the surface mass balance and the surface chemical composition. Once the ablation mass rate has been computed, the erosion rate can be easily derived by its definition $\dot{s}=\dot{m} / \rho_{s}$. The surface temperature is computed from the surface energy balance using the Newton's iterative procedure. At each computational fluid dynamics (CFD) iteration, the surface temperature, the ablation mass rate, and the wall chemical composition are continuously updated until a steady-state condition is reached. The computational domain is defined by the nozzle geometry. The nozzle is characterized by subsonic inflow boundary conditions describing combustion chamber (total temperature and total pressure are enforced together with the flow direction and chemical composition), supersonic outflow, symmetry axis and solid wall. The inlet flow is a mixture of gases derived from chemical equilibrium calculations.

The present model has been validated in [9] for ablating surfaces where diffusion-limited erosion mechanism can be assumed, i.e., for sufficiently high nozzle surface temperatures. In particular, validation of the diffusion-limited model has been made by comparison with recession rates measured in the BATES (Ballistic Test and Evaluation System) motor experimental data [7, 14] for the motor operating conditions reported in Table 1. The BATES was developed 
Table 1 Mass fractions, pressure, temperature, and aluminum content for experiments $[7,14]$

\begin{tabular}{lllllccccc}
\hline$y_{\mathrm{CO}}$ & $y_{\mathrm{CO}_{2}}$ & $y_{\mathrm{HCl}}$ & $y_{\mathrm{H}_{2}}$ & $y_{\mathrm{H}_{2} \mathrm{O}}$ & $y_{\mathrm{N}_{2}}$ & $y_{\mathrm{Al}_{2} \mathrm{O}_{3}}$ & $p_{c}$, bar & $T_{c}, \mathrm{~K}$ & $\mathrm{Al}, \%$ \\
\hline 0.175 & 0.04 & 0.24 & 0.02 & 0.145 & 0.10 & 0.28 & 69 & 3580 & 15 \\
0.18 & 0.025 & 0.23 & 0.02 & 0.105 & 0.10 & 0.34 & 69 & 3655 & 18 \\
0.20 & 0.015 & 0.195 & 0.02 & 0.07 & 0.10 & 0.40 & 69 & 3715 & 21 \\
0.20 & 0.005 & 0.190 & 0.02 & 0.045 & 0.10 & 0.44 & 69 & 3750 & 24 \\
0.20 & 0.005 & 0.190 & 0.02 & 0.025 & 0.10 & 0.46 & 69 & 3745 & 27 \\
\hline
\end{tabular}

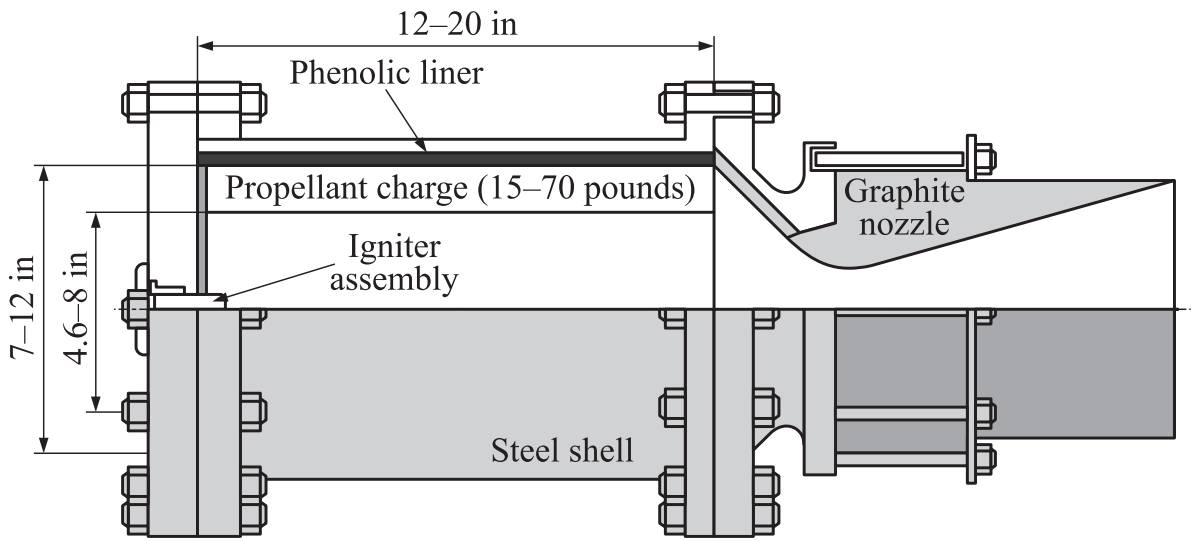

Figure 1 The 70-pound BATES motor [14]

in the early 1960s and developed over the past 40 years. This system has become the standard for measuring and comparing solid-propellant performance in USA [14]. The 70-pound BATES motor is shown in Fig. 1. The computed erosion rate distributions along the nozzle length as a function of the aluminum content of the propellant are plotted in Fig. 2 together with the experimental data measured at the throat.

\section{RESULTS}

The model described in the preceding sections is implemented to simulate the nozzle erosion in practical solid rocket motor environments. The nozzle geometry employed is the one used in the BATES rocket motor [14] (see Fig. 1) and it has been rebuilt on the basis of the main geometric parameters (throat radius, overall dimensions, and divergence angle) reported in [14]. 


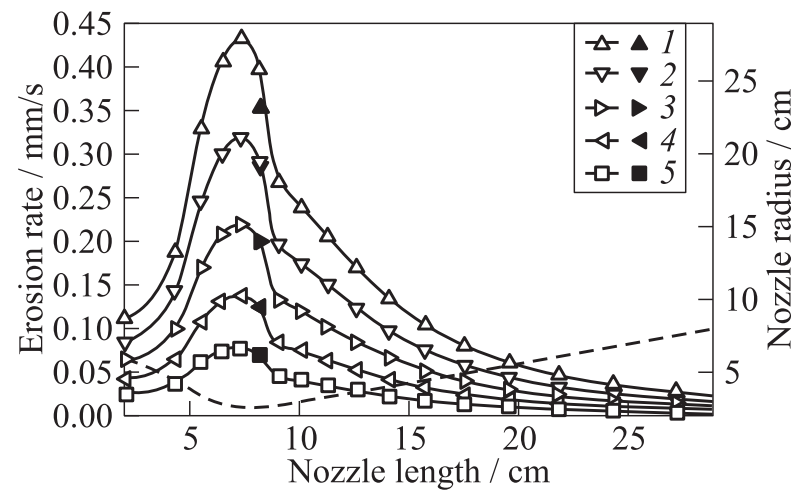

Figure 2 Erosion rate distribution for propellants with different aluminum content: $1-15 \%\left(T_{0}=3580 \mathrm{~K}\right) ; 2-18 \%\left(T_{0}=3655 \mathrm{~K}\right) ; 3-21 \%\left(T_{0}=3715 \mathrm{~K}\right) ; 4-$ $24 \%\left(T_{0}=3750 \mathrm{~K}\right)$; and $5-27 \%\left(T_{0}=3745 \mathrm{~K}\right)$. Empty signs refer to computed distributions and black signs to experimental data [14]. Dashed curve - nozzle contour

As shown in Fig. 3, the adopted grid geometry has been modified with respect to the real nozzle geometry. The BATES nozzle, in fact, is made of a conical convergent section with an angle of $45^{\circ}$ which would have caused a certain ambiguity in imposing the inflow boundary condition due to the unknown velocity direction at the inlet. For that reason, the convergent section has been reproduced using a parabolic curve which becomes parallel to the nozzle axis at the inlet section so that an axial inlet velocity profile can be assigned. Since the length of the wall is important because it affects the boundary-layer thickness and, hence, the heat and mass transfer rate, the to-

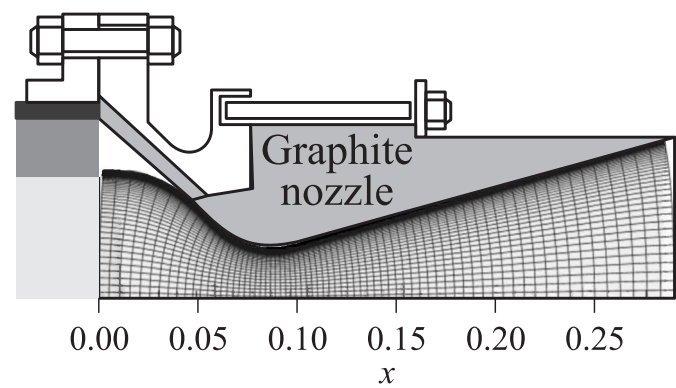

Figure 3 Nozzle grid for BATES motor 
Table 2 Nozzle inlet flow conditions

\begin{tabular}{cccccccccc}
\hline$y_{\mathrm{CO}}$ & $y_{\mathrm{CO}_{2}}$ & $y_{\mathrm{HCl}}$ & $y_{\mathrm{H}_{2}}$ & $y_{\mathrm{H}_{2} \mathrm{O}}$ & $y_{\mathrm{N}_{2}}$ & $y_{\mathrm{Al}_{2} \mathrm{O}_{3}}$ & $p_{c}$, bar & $T_{c}, \mathrm{~K}$ & $\mathrm{Al}, \%$ \\
\hline 0.18 & 0.025 & 0.23 & 0.02 & 0.105 & 0.10 & 0.34 & 69 & 3655 & 18 \\
\hline
\end{tabular}

tal wall length of the parabolic curve is equal to that of the 45 degree cone (see Fig. 3). The computational domain is subdivided into $70 \times 80$ grid points in the axial and radial directions, respectively. In the radial direction, meshes are clustered near the nozzle surface such to ensure a value of $y^{+}<1.0$ all along the nozzle length to accurately capture the near-wall phenomena. A grid sensitivity analysis has been carried out to ensure that all the presented steadystate results are grid independent. The scale effect on the overall nozzle erosion process is evaluated on a scale reduction (1:10) of the reference nozzle geometry. To analyze the boundary layer thickness at nozzle entrance and its effect on the erosion rate, a constant area duct is added upstream of the inlet section.

The hot exhaust gas flowing in the nozzle consists of the combustion products of a typical metalized AP/HTPB (ammonium perchlorate/hydroxyl-terminated polybutadiene) composite propellant, whose mass fractions are reported in Table 2. These mass fractions have been determined by chemical equilibrium calculations at a chamber pressure of 69 bar. The oxidizing species considered are $\mathrm{H}_{2} \mathrm{O}$ and $\mathrm{CO}_{2}$. Other oxidizing species have not been considered having a much lower mass fraction and, hence, a negligible influence on the erosion process. The equilibrium mixture would include condensed $\mathrm{Al}_{2} \mathrm{O}_{3}$; however, only single-phase

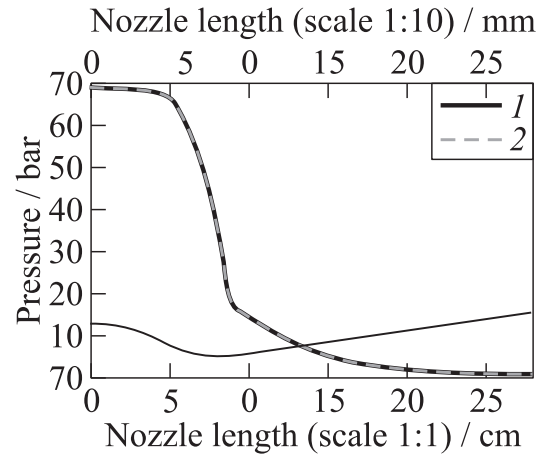

(a)

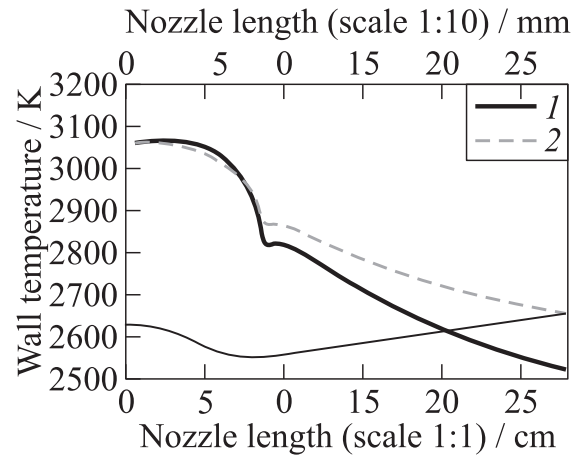

(b)

Figure 4 Scale effect on wall pressure $(a)$ and temperature $(b): 1-$ scale 1:10; and 2 - scale 1:1. Thin curve - nozzle contour 


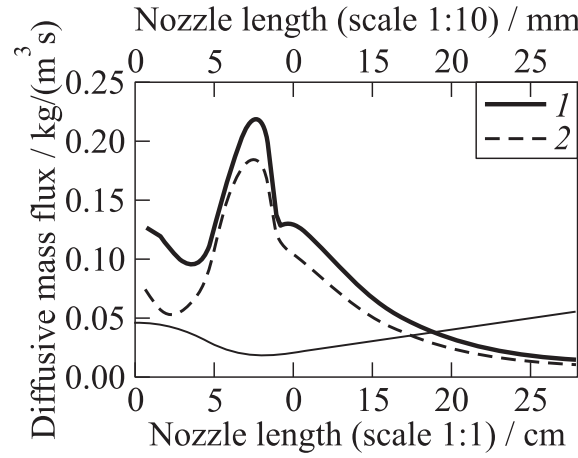

(a)

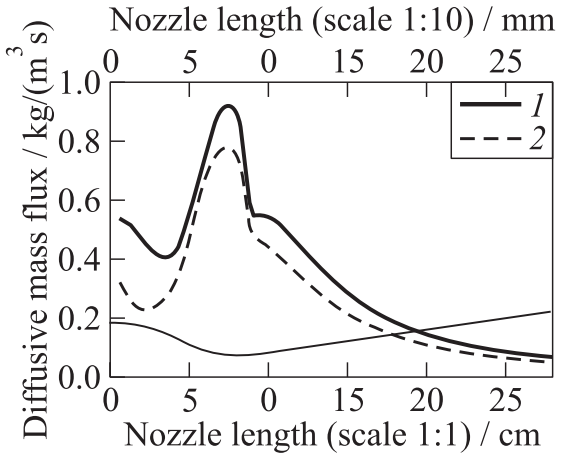

(b)

Figure 5 Scale effect on oxidizing species diffusion: (a) $\mathrm{CO}_{2}$ wall diffusive mass flux; and $(b) \mathrm{H}_{2} \mathrm{O}$ wall diffusive mass flux: 1 - scale 1:10; and 2 - scale 1:1. Thin curve nozzle contour

Nozzle length (scale 1:10) / $\mathrm{mm}$

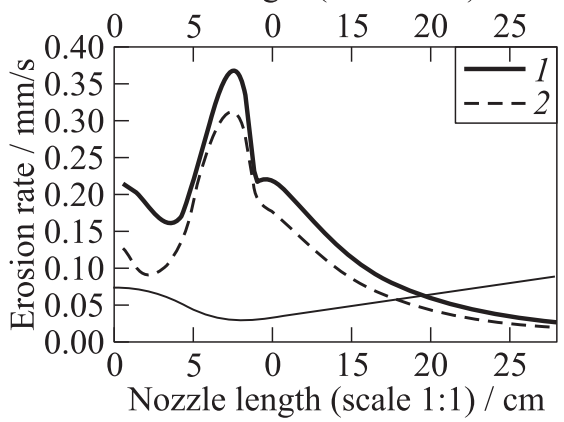

(a)

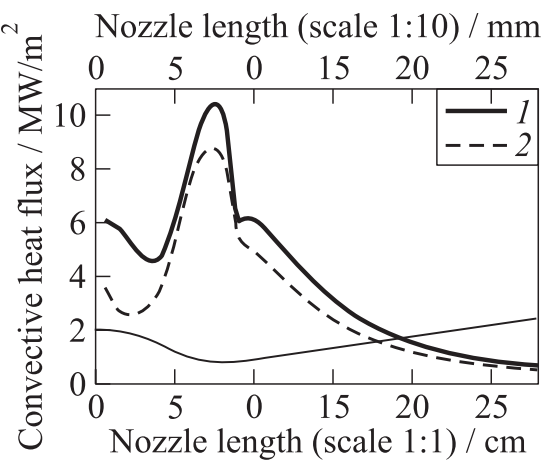

(b)

Figure 6 Scale effect on erosion rate $(a)$ and wall heat flux $(b): 1$ - scale 1:10; and 2 - scale 1:1. Thin curve - nozzle contour

simulations are carried out where all the $\mathrm{Al}_{2} \mathrm{O}_{3}$ present in the exhaust gas is assumed to be in the gas phase.

The obtained results with the present approach for the scale effect analysis are reported in Figs. 4-6. Results obtained with the reference nozzle and with the 1:10 scaled version show almost no differences in the core-flow region. The main differences are experienced in the boundary layer and at the nozzle surface. 
Figure 4 shows the scale effect on the wall pressure and temperature profiles. It can be seen that the wall pressure is unaffected by the scale change while the surface temperature presents some differences, especially in the divergent section with the scaled nozzle experiencing a lower wall temperature. The knee visible in the wall temperature distribution is due to the change of curvature between the throat and the conical divergent section of the nozzle and is made more evident by the scaled nozzle. Considering the following heterogeneous oxidizing reactions:

$$
\begin{aligned}
& \mathrm{C}_{(\mathrm{s})}+\mathrm{H}_{2} \mathrm{O} \rightleftharpoons \mathrm{CO}+\mathrm{H}_{2} ; \\
& \mathrm{C}_{(\mathrm{s})}+\mathrm{CO}_{2} \rightleftharpoons 2 \mathrm{CO},
\end{aligned}
$$

it can be seen that a single mole of solid carbon $\mathrm{C}_{(\mathrm{s})}$ can be consumed either with a single mole of $\mathrm{H}_{2} \mathrm{O}$ or $\mathrm{CO}_{2}$. Hence, the erosion rate contribution due to each oxidizing species can be obtained by mass conservation equation considering that each oxidizing species diffusing to the nozzle wall is completely consumed at the surface (diffusion-limited regime). The more oxidizing species are diffused to the surface, the more the nozzle surface is consumed.

Figure 5 shows the wall diffusive mass fluxes of the two oxidizing species, $\mathrm{H}_{2} \mathrm{O}$ and $\mathrm{CO}_{2}$. It can be clearly seen that the mass flow rate of the oxidizing species is higher for the scaled nozzle due to the scale effect on the boundary-layer structure.

Higher diffusion of oxidizing species leads to higher erosion rate as confirmed by Fig. $6 a$ where the erosion rate at the throat is increased by $20 \%$ in the scaled nozzle. Note that this increase is even more severe in terms of throat area increase and, hence, performance loss, due to the lower throat radius. Figure $6 b$ shows the convective heat flux distributions for the two cases with the scaled nozzle showing a higher heat flux. The nozzle scaling has a clear effect on the boundary layer structure leading to an increase of the diffusive mass and energy transfer and, hence, to a higher heat flux and erosion rate. A higher convective heat flux produces an increase of surface temperature while a higher erosion rate produces a reduction of surface temperature because of the heat absorption of the ablation process. However, due to the nonlinear nature of the surface mass and energy balance coupling (1) and (2), the surface temperature is reduced in the scaled geometry as shown in Fig. $4 b$.

The effect of the boundary layer thickness on the erosion process is now analyzed. As Fig. 6 clearly shows, there is a clear correlation between the heat flux distribution and the erosion rate distribution. Because the convective heat transfer depends on boundary layer evolution, it is important to analyze the boundary layer growth on rocket nozzle walls. In rapidly accelerating flows, like those inside a rocket nozzle, the boundary layer thickness may decrease in the flow direction, reaching a minimum at the throat section. 


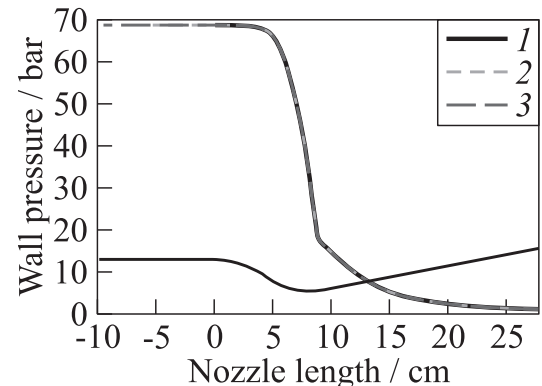

(a)

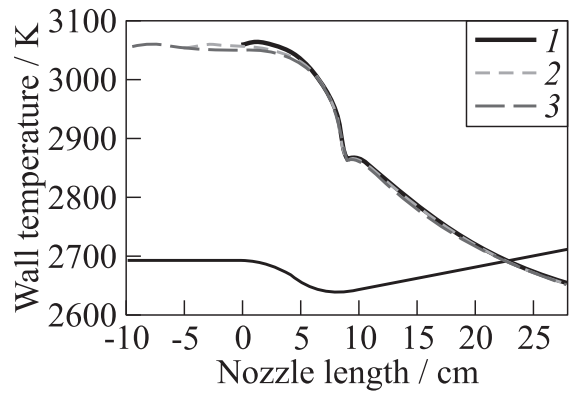

(b)

Figure 7 Boundary layer thickness effect on wall pressure $(a)$ and temperature $(b)$ : $1-x_{c}=0 ; 2-0.5 l_{c} ;$ and $3-x_{c}=l_{c}$. Thin curve - nozzle contour

This effect has been first demonstrated by the approximate calculation of Bartz [15] who made the following conclusions:

(i) the value of the boundary layer thickness tends to be a minimum near the throat, causing a maximum heat transfer rate in this section; and

(ii) the boundary layer thickness is not strongly dependent on the boundary layer thickness at entrance to the nozzle.

The first conclusion is a well established knowledge and Fig. 6 shows that the erosion rate follows the same trend as the convective heat flux with a maximum a bit ahead of the throat. To analyze the effect of the boundary layer thickness at the nozzle inlet, a constant area duct is added upstream of the inlet section (one equal to one half of the convergent length and one equal to one convergent length) to produce a larger boundary layer thickness at the inlet section. The obtained results show almost no differences in the core-flow region as for the scale effect analysis.

Figure 7 shows the effect of entrance boundary layer thickness on the wall pressure and temperature profiles. In this case, neither the surface pressure nor the surface temperature are affected by the boundary layer thickness at the nozzle entrance.

Figures 8 and 9 show the effect of duct length on the diffusive mass flux of oxidizing species, erosion rate, and convective heat flux distributions. Adding a constant area duct ahead of the nozzle inlet section generates a larger boundary layer thickness at the nozzle entrance, hence reducing the gradients and consequently the diffusive mass and energy fluxes. This effect is more evident in the convergent section, is reduced after the throat, and finally almost vanishes at the nozzle exit. Even if it can be concluded that the boundary layer thickness is 


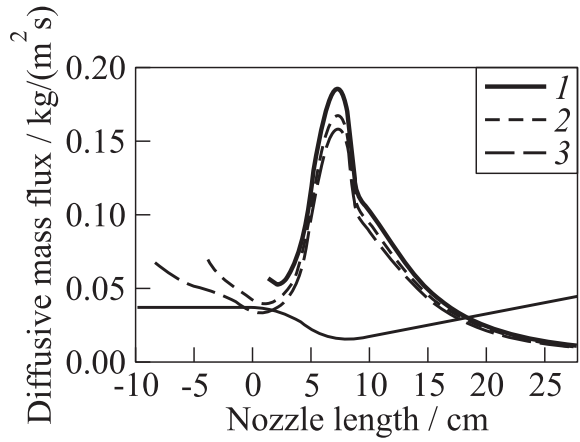

(a)

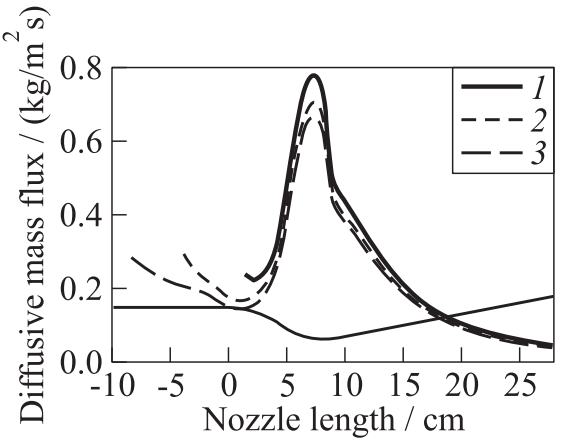

(b)

Figure 8 Boundary layer thickness effect $\left(1-x_{c}=0 ; 2-0.5 l_{c}\right.$; and $\left.3-x_{c}=l_{c}\right)$ on oxidizing species diffusion: $\mathrm{CO}_{2}(a)$ and $\mathrm{H}_{2} \mathrm{O}(b)$ wall diffusive mass flux. Thin curve - nozzle contour

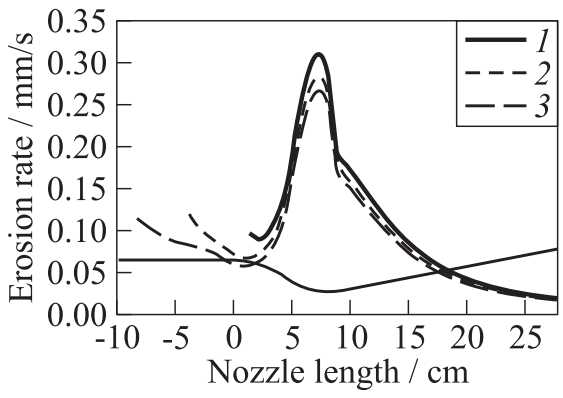

(a)

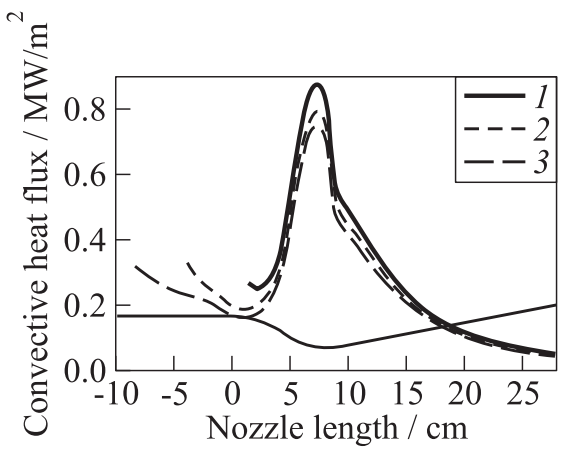

(b)

Figure 9 Boundary layer thickness effect on erosion rate $(a)$ and wall heat flux $(b)$ : $1-x_{c}=0 ; 2-0.5 l_{c}$; and $3-x_{c}=l_{c}$. Thin curve - nozzle contour

not strongly dependent on its thickness at entrance, the latter affects both heat flux and erosion rate at the throat section.

Figure 10 shows the combined effect of the added duct length and scale reduction on the throat erosion rate. With a duct length of one half of the convergent length, the erosion rate of the reference nozzle is reduced by $9 \%$. This reduction is not negligible, especially if the uncertainty on the boundary layer thickness at entrance is high. However, a 14 percent reduction is obtained for a duct length equal to one convergent length, showing that the erosion rate decreases less than linearly with the added duct length exhibiting an asymptotic 


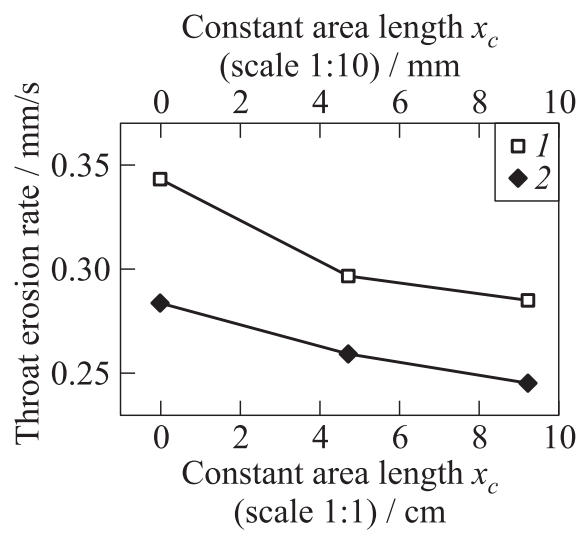

Figure 10 Scale and boundary layer thickness effect on throat erosion rate: 1 scale $1: 10 ;$ and 2 - scale $1: 1$

behavior. The scaled nozzle shows a similar trend with respect to the added length, with a more pronounced nonlinear behavior.

\section{CONCLUDING REMARKS}

A general model based on a full Navier-Stokes approach is adopted to examine both the scale and the inlet boundary layer thickness effect on the thermochemical ablation of $\mathrm{C} / \mathrm{C}$ heat protection materials in SRM environments. This problem is of critical importance to predict nozzle erosion rate and, hence, motor performance.

The model includes all the relevant physics of the hot-gas flow, the ablation process, and the internal heat conduction into the material. The two regions, gas and solid, are coupled at the surface by appropriate energy and mass balances allowing the surface conditions to be solved as part of the overall solution. The surface thermochemistry model is based on heterogeneous chemical equilibrium and can account for both surface oxidation and sublimation. The results show that the nozzle scaling has a direct effect on the boundary layer structure leading to an increase of the diffusive mass and energy transfer and, hence, to a higher heat flux and erosion rate. From a performance perspective, this behavior is made even more severe by the reduced throat radius, which generates a higher area increase due to the reduced initial area. The results also show that the erosion rate at the throat section is sensitive to the boundary layer thickness at the nozzle entrance while its influence tend to vanish in the divergent section. This effect, which is basically due to the different boundary layer thickness in 
the throat section and, hence, to the different heat and mass fluxes experienced, is made more evident by the reduction of the nozzle overall dimensions and, thus, could motivate the need for a better modeling of the boundary layer at the nozzle entrance.

\section{ACKNOWLEDGMENTS}

Authors acknowledge the contribution of A. Turchi for executing some of the presented computations during his graduation thesis.

\section{REFERENCES}

1. Delaney, L. J., L. C. Eagleton, and W. H. Jones. 1964. A semiquantitative prediction of the erosion of graphite nozzle inserts. AIAA J. 2(8).

2. McDonald, A. J., and P. O. Hedman. 1965. Erosion of graphite in solid-propellant combustion gases and effects on heat transfer. AIAA J. 3(7).

3. Klager, K. 1977. The interaction of the efflux of solid propellants with nozzle materials.Propellants Explosives 2(3):55-63.

4. Kuo, K.K., and S.T. Keswani. 1985. A comprehensive theoretical model for carbon-carbon composite recession. Combust. Sci. Technol. 42(3-4):145-64.

5. Keswani, S. T., and K. K. Kuo. 1986. Validation of an aerothermochemical model for graphite nozzle recession and heat-transfer processes. Combust. Sci. Technol. 47(3-4):177-92.

6. Borie, V., J. Brulard, and G. Lengelle. 1989. Aerothermochemical analysis of carbon-carbon nozzle regression in solid-propellant rocket motors. J. Propul. Power $5(6): 665-73$.

7. Geisler, R.L. 1981. The prediction of graphite rocket nozzle recession rates. 1981 JANNAF Propulsion Meeting Proceedings. New Orleans, LA. CP/A Publication 342. 5:173-96.

8. Thakre, P., and V. Yang. 2008. Chemical erosion of carbon-carbon/graphite nozzles in solid-propellant rocket motors. J. Propul. Power 24(4):822-33.

9. Bianchi, D., F. Nasuti, and E. Martelli. 2009. Coupled analysis of flow and surface ablation in carbon-carbon rocket nozzles. J. Spacecraft Rockets 46(3).

10. Nasuti, E., and M. Onofri. 1996. Analysis of unsteady supersonic viscous flows by a shock fitting technique. AIAA J. 34(7):1428-34.

11. Moretti, G. 1987. A technique for integrating two-dimensional Euler equations. Computer Fluids 15(1):59-75. 
12. Gordon, S., and B. J. McBride. 1994. Computer program for calculation of complex chemical equilibrium compositins and applications. NASA AP 1311.

13. Spalart, P. R., and S. R. Allmaras. 1994. A one-equation turbulence model for aerodynamic flow. La Recherche Aerospatiale 1:5-21.

14. Geisler, R. L., and C. W. Beckman. 1998. The history of the BATES Motors at the air force rocket propulsion laboratories. AIAA Paper No. 98-3981.

15. Bartz, D. R. 1955. An approximate form of compressible turbulent boundary layer development in convergent-divergent nozzles. Trans. ASME 77. 